\title{
PERANCANGAN APLIKASI MONITORING KESEHATAN MASYARAKAT DESA SIMPANG EMPAT BERBASIS WEB
}

\author{
Sefto Pratama ${ }^{1)}$ \\ ${ }^{1}$ Fakultas Teknologi Informasi, Universitas Islam Kalimantan Muhammad Arsyad Al Banjari (Sefto Pratama) \\ email : Seftopratama.bjm@gmail.com
}

\begin{abstract}
Abstrak
Kesehatan merupakan hal yang sangat penting bagi kita sebagai manusia, namun kadang menjaga kesehatan menjadi sangat sulit ketika kita dihadapkan dengan kebiasaan-kebisaan buruk yang biasanya tanpa kita sadari kita lakukan, kebiasaan tersebut seperti membuang sampah sembarangan, makan makanan yang tidak sehat. Desa Simpang Empat merupakan desa yang terletak di Kecamatan Kertak Hanyar Kabupaten Banjar, desa ini terletak di area persawahan dan di huni oleh masyarakat yang rata-rata hidupnya dari kalangan menengah kebawah, yang diantara mereka masih kurang menyadari apa itu pentingnya menjaga kesehatan lingkungan. Maka dari itu dengan ini peneliti merancang sebuah aplikasi yang diharapkan mampu dalam memonitoring kesehatan masyarakat kususnya masyarakat yang tinggal di Desa Simpang Empat, agar informasi kesehatan masyarakat dapat terorganisir dengan baik, dan dapat dilakukan tidak lanjut apabila mulai terjadi dampak buruk dari kesehatan masyarakat.
\end{abstract}

Keywords: Aplikasi, Monitoring, Kesehatan, Masyarakat, Web

\section{PENDAHULUAN}

Menjaga kesehatan merupakan kewajiban bagi setiap orang, namun sulitnya dalam menumbuhkan kesadaran dalam menjaga kesehatan saat ini menjadi momok yang sangat menakutkan, disebabkan oleh banyak hal, salah satunya kesenjangan atau ketimpangan sosial yang terjadi di masyarakat sekarang ini, faktor pendidikan, dan juga faktor edukasi tentang pentingnya menjaga kesehatan lingkungan khususnya lingkungan keluarga.

Banyak sekali penyakit yang akan timbul apabila lingkungan tidak di jaga atau kotor, salah satunya penyakit Demam Berdarah, penyakit ini disebabkan oleh nyamuk Aedes Aegypti, nyamuk ini bersarang atau bertelur di tempat yang biasanya ada genangan air, atau tempat kotor.

Dari uraian diatas maka dibuatlah sebuah Aplikasi yang memonitoring kesehatan masyarakat kususnya sekitar Desa Simpang Empat, diharapkan dengan aplikasi ini akan

Jurnal Ilmiah "Technologia" memudahkan bagi masyarakat dalam melihat perkembangan kesehatan desa, hingga menumbuhkan kesadaran bagi masyarakat dalam menjaga kesehatan diri, keluarga maupun masyarakat.

\section{METODE PENELITIAN}

Pada penelitian ini penulis menggunakan beberapa metode pengumpulan data sebagai berikut :

a. Metode Observasi

Observasi atau pengamatan merupakan salah satu teknik pengumpulan data atau fakta yang cukup efektif untuk mempelajari suatu sistem. Observasi yang dilakukan yaitu datang langsung melihat dan melakukan pengamatan kegiatan masyarakat dan lingkungan sekitar Desa Simpang Empat..

b. Metode Wawancara 
Wawancara merupakan salah satu teknik pengumpulan data yang penting dan banyak dilakukan dalam pengembangan Aplikasi. Wawancara dilakukan dengan masyarakat Desa Simpang Empat untuk mengumpulkan data secara tatap muka langsung dengan orang yang diwawancarai. Adapun orangorang yang diwawancarai adalah kepala Desa dan Masyarakat sekitar, dan petugas Pustu (Puskesmas Pembantu).

Analisis sistem adalah suatu proses mengumpulkan dan menginterpretasikan kenyataan-kenyataaan yang ada, mendiagnosa persoalan dan menggunakan keduanya untuk memperbaiki sistem. Pada tahap ini penulis lakukan adalah :

a. Mengidentifikasi masalah untuk mendapat pengertian sebenarnya dari masalah yang dihadapi yaitu dengan mengidentifikasikan penyebab masalah dan bagaimana langkah untuk menyelesaikannya.

b. Memahami sistem kerja yang ada dengan mengumpulkan data hasil penelitian dan memahami sistem yang ada.

c. Menganalisa kelemahan sistem dan kebutuhan informasi

\section{Tahapan Penelitian}

Tahapan penelitian ini antara lain :

1. Pengajuan proposal penelitian

2. Penentuan objek penelitian

3. Kajian teori untuk menentukan kriteria

4. Pengumpulan data primer dan sekunder

5. Pengolahan data

6. Pembuatan sistem

7. Pengujian sistem

8. Pembuatan laporan

\section{Objek Penelitian}

Objek penelitian ini dilakukan di Desa Simpang Empat Kertak Hanyar Kabupaten Banjar.

Jurnal Ilmiah "Technologia"

\section{Metode Pengumpulan Data}

Pada penelitian ini penulis menggunakan beberapa metode pengumpulan data sebagai berikut :

\section{Metode Observasi}

Observasi atau pengamatan merupakan salah satu teknik pengumpulan data atau fakta yang cukup efektif untuk mempelajari suatu sistem. Observasi adalah pengamatan langsung para pembuat keputusan berikut lingkungan fisiknya atau pengamatan langsung suatu kegiatan yang sedang berjalan. Pada tahap ini penulis melakukan pengamatan terhadap kegiatan, proses, dan alur masuk dan bagaimana sebuah sistem pencatatan berjalan.

2. Metode Wawancara

Wawancara merupakan salah satu teknik pengumpulan data yang penting dan banyak dilakukan dalam pengembangan Aplikasi. Wawancara memungkinkan analis sistem sebagai pewawancara untuk mengumpulkan data secara tatap muka langsung dengan orang yang diwawancarai. Adapun orang-orang yang diwawancarai adalah kepala perpustakaan, petugas perpustakaan serta siswa SMPN 1 Kertak Hanyar.

\section{Tahap-Tahap Pembuatan Sistem}

Dalam pengembangan sistem ini, ada beberapa tahapan yang harus dilakukan. Adapun tahapan tersebut adalah sebagai berikut:

\section{Analisis Sistem yang berjalan}

a) Tidak adanya sistem yang jelas tentang informasi kesehatan di Desa Simpang Empat.

b) Akibatnya ketidaktahuan masyarakat tentang pentingnya menjaga kesehatan membuat kesehatan masyarakat menjadi terabaikan.

c) Akhirnya masyarakat sering mengalami gangguan kesehatan akibat tidak ada sistem yang memonitoring kesehatan masyarakat. 


\section{Analisis Kebutuhan Sistem}

a) Saat ini masih belum ada sistem aplikasi yang memonitoring kesehatan masyarakat, sehingga membuat sulitnya dalam memonitoring kesehatan masyarakat, hanya ada catatan dari petugas kesehatan di PUSTU (Puskesmas Pembantu) yang berada di Desa Simpang Empat.

b) Dengan hanya berkas catatan tersebut memungkinkan terjadi rusak dan hilangnya dokumen tersebut.

c) Dari permasalahan diatas maka dibutuhkan sebuah sistem aplikasi yang dapat membantu dalam mengelola data kesehatan masyarakat, sehingga memudahkan bagi tenaga kesehatan dan masyarakat dalam

memonitoring kesehatan lingkungan masyarakatnya.

\section{Perancangan Sistem}

Proses perancangan yang baik diperlukan untuk pembuatan program tak terkecuali dalam pembuatan Aplikasi yang baik. Perancangan sistem secara terperinci, dilakukan dengan cara:

\section{Waterfall Aplikasi Monitoring Kesehatan Masyarakat Desa Simpang Empat Berbasis WEB}

Skema alur urutan proses dalam persiapan pembuatan Aplikasi Monitoring Kesehatan Masyarakat.

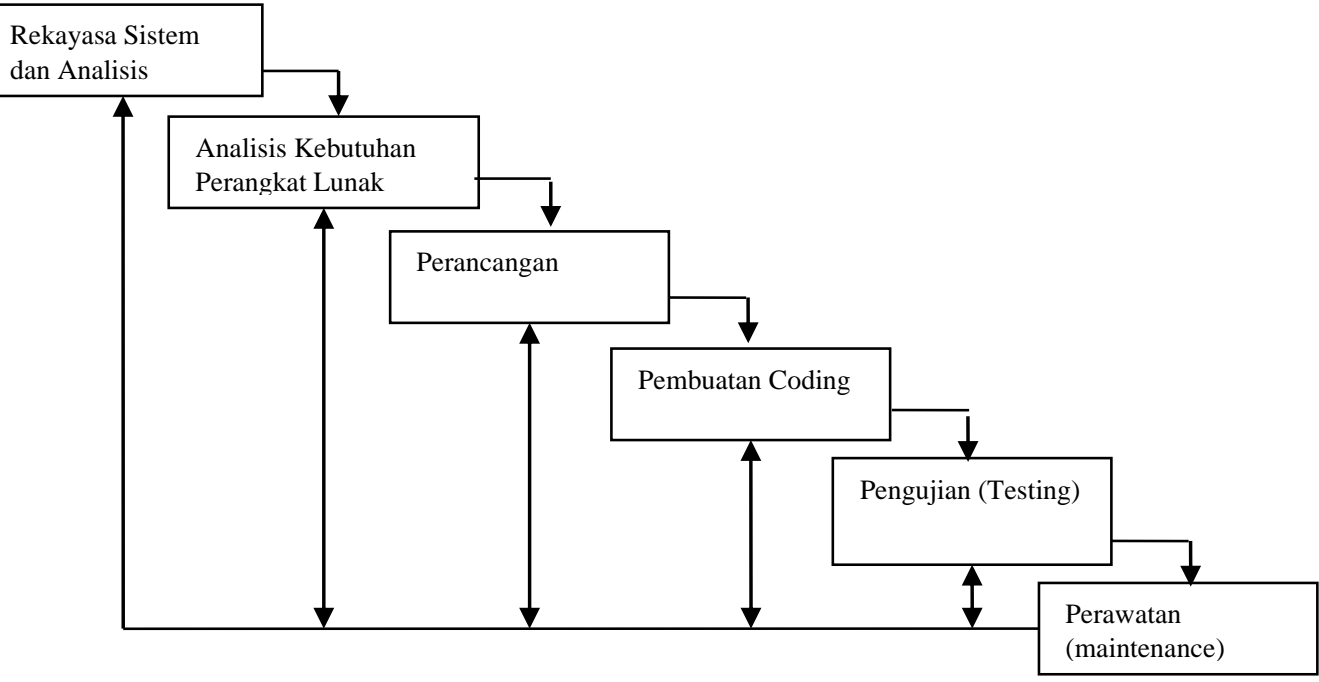

Gambar 1 Metode Waterfall Aplikasi Monitoring Kesehatan Masyarakat Berbasis Web 


\section{Rancangan Tampilan}

Rancangan interface tampilan awal Aplikasi perpustakaan berbasis web SMPN 1 Kertak Hanyar adalah tampilan Login.

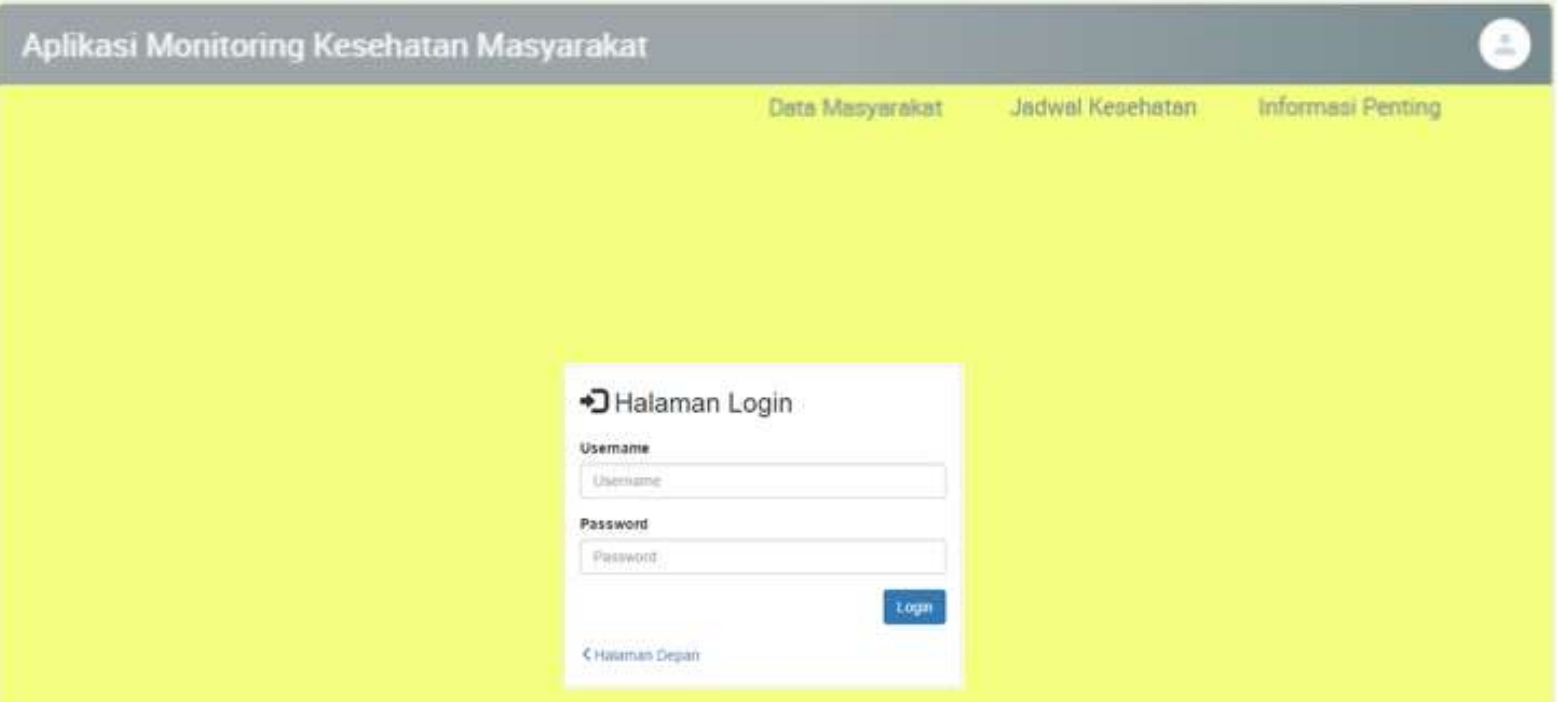

Gambar 2 interface login pada Aplikasi Monitoring Kesehatan Masyarakat Desa Simpang Empat

\section{Rancangan Output dan Laporan}

Rancangan interface tampilan hasil Aplikasi Monitoring Kesehatan Masyarakat Desa Simpang Empat.

\section{Aplikasi Monitoring Kesehatan Masyarakat}

Data Masyarakat

Jadwal Kesehatan

Informsai Penting

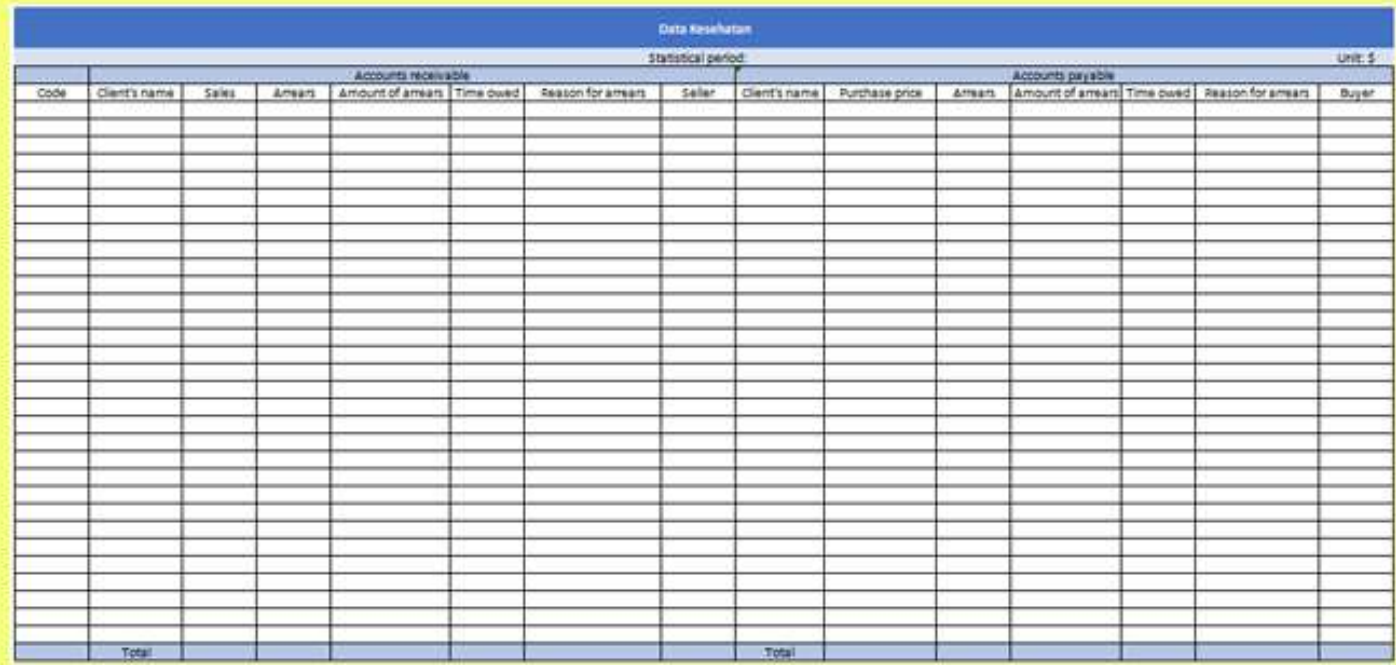

Jurnal Ilmiah "Technologia” 
Gambar 3 Tampilan Laporan Data Masyarakat Desa Simpang Empat

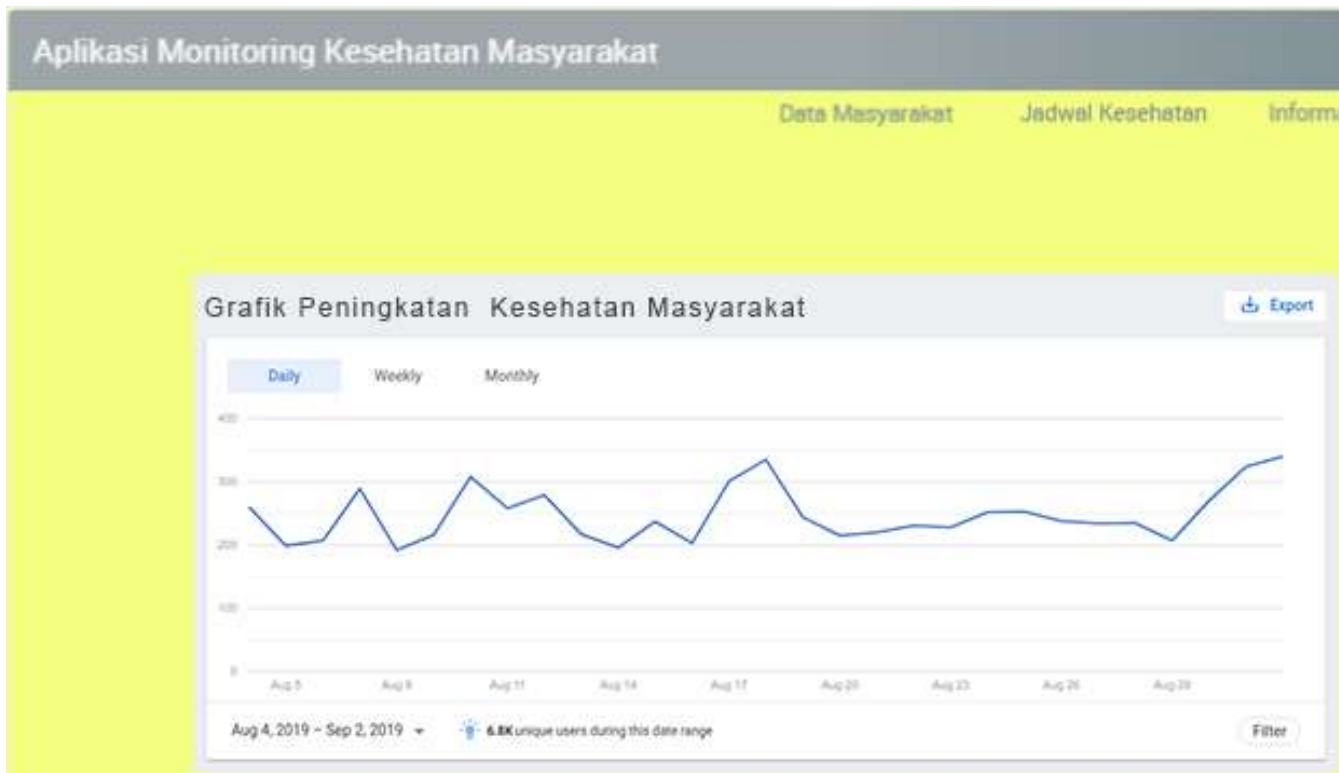

Gambar 4 Tampilan Laporan Informasi Grafik Kesehatan Masyarakat Desa Simpang Empat

\section{Aplikasi Monitoring Kesehatan Masyarakat}

Data Masyaraicat

Jadwal Kesehatan

Informssi Penting

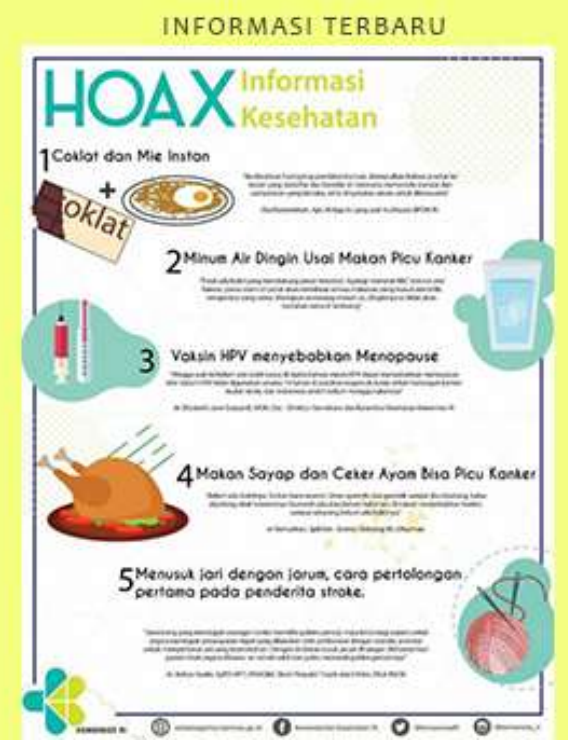

Gambar 5 Tampilan Informasi terbaru Tentang Kesehatan 


\section{HASIL DAN PEMBAHASAN}

\section{Implementasi}

Tahap implementasi sistem dilakukan penerjemahan kebutuhan pembangunan Aplikasi Monitoring Kesehatan Desa Simpang Empat Berbasis WEB kedalam representasi perangkat lunak sesuai dengan hasil analisis yang telah dilakukan. Setelah implementasi maka dilakukan pengujian sistem yang baru dimana akan dilihat kekurangan - kekurangan pada aplikasi yang baru untuk selanjutnya diadakan pengembangan sistem.

\section{Spesifikasi Sistem Aplikasi}

Spesifikasi Aplikasi Monitoring Kesehatan Masyarakat Desa Simpang Empat Berbasis Web menggunakan spesifikasi perangkat keras dan perangkat lunak sebagai berikut ;

1. Perangkat keras pendukung

- Processor Intel Core i5

- RAM 4 GB DDR4

- LCD 14 Inch

- Hardisk 1 TB

2. Perangkat lunak pendukung

- Sistem Operasi Windows 10

- Pemprograman PHP

- Notepad++

- Data Base Xampp My SQL

- Web Browser

\section{Tampilan Antar Muka Aplikasi}

\section{Halaman Menu Utama}

Pada halaman menu utama user yang sudah login dapat menggunakan semua menubar yang sudah tersedia.

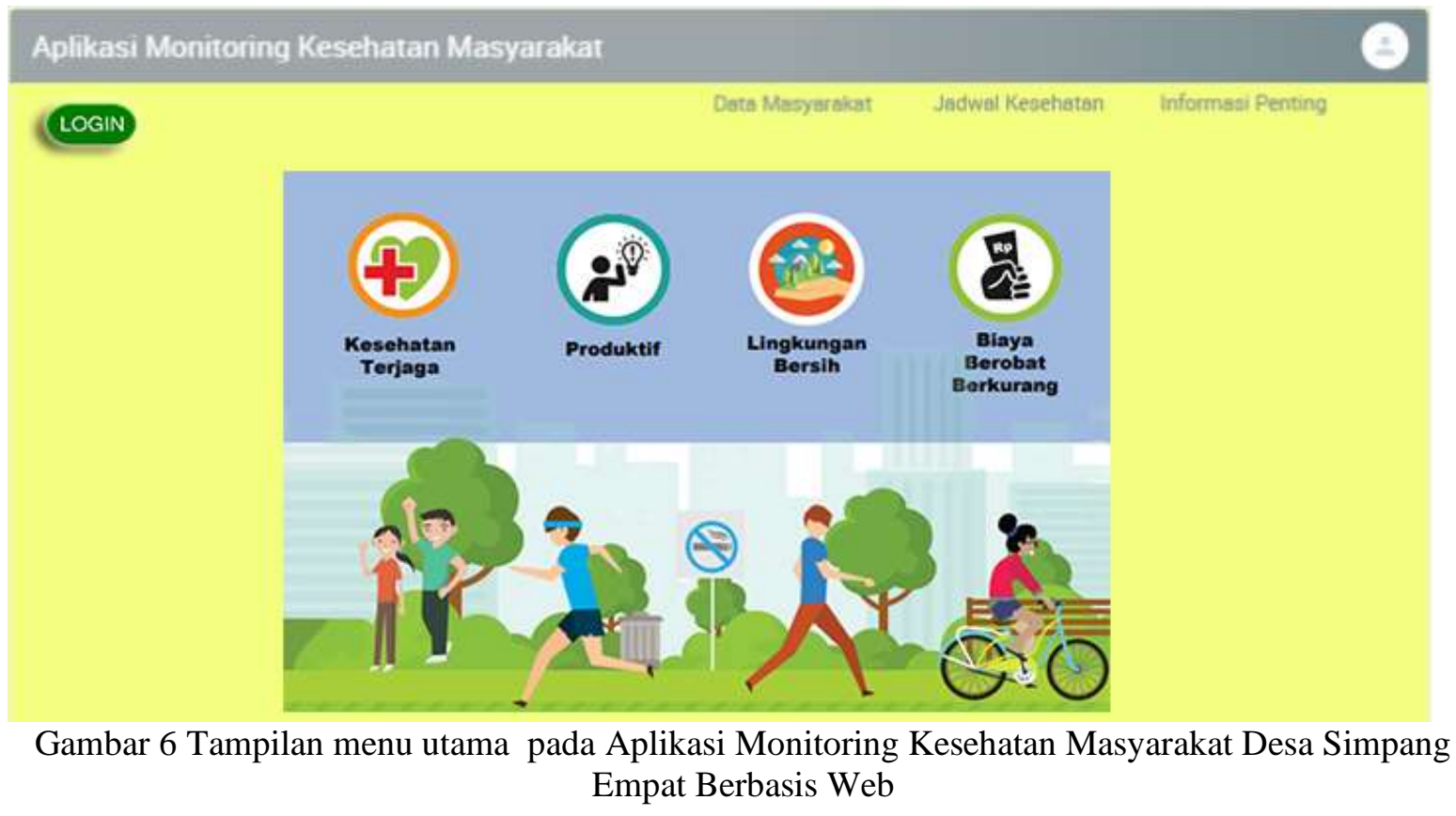

\section{Tampilan Input Data}

Jurnal Ilmiah "Technologia” 
Pada form penginputan data bisa disesuaikan dengan keperluan, seperti yang yang telah tersedia berupa :

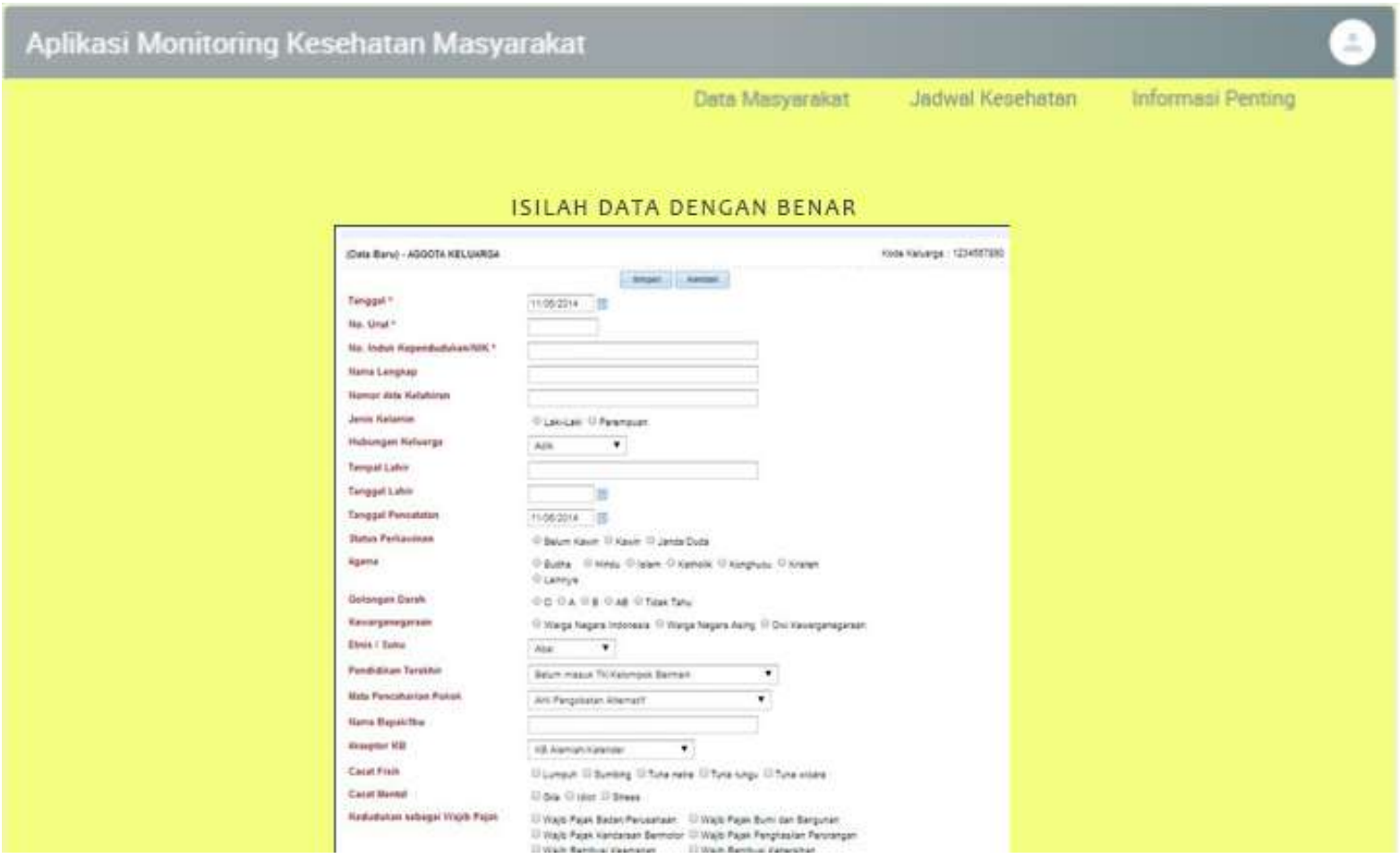

Gambar 7 Form Input Data Masyarakat

Aplikasi Monitoring Kesehatan Masyarakat

Data Masyarakat Jadwal Kesehatan Informasi Penting

MASUKAN DATA PASIEN

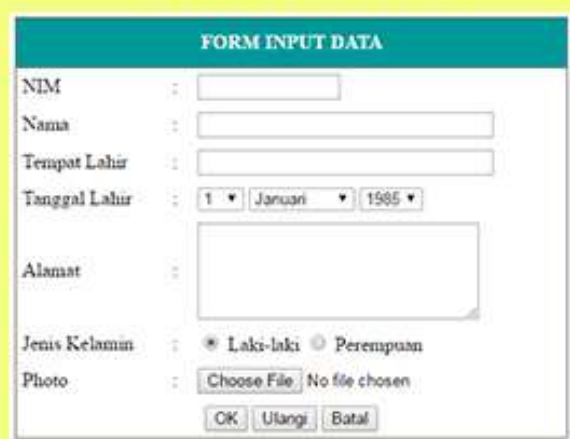

Gambar 8 Form Input Data Pasien 


\section{KESIMPULAN}

Berdasarkan hasil dari evaluasi yang telah dilaksanakan penulis, maka penulis dapat menyimpulkan bahwa :

1. Pemanfaatan Aplikasi Monitoring Kesehatan Masyarakat Desa Simpat Empat diharapkan dapat membantu dalam proses memonitor kesehatan masyarakat, yang berimbas kepada meningkatkan kesadaran akan pentingnya kesehatan bagi masyarakat.

2. Pemanfaatan Aplikasi Monitoring Kesehatan ini bisa menjadi referensi bagi desa-desa di daerah lain.

3. Pemanfaatan informasi kesehatan terbaru dapat menjadi acuan yang benar bagi masyarakat diantara maraknya informasi hoax yang beredar di masyarakat .

\section{REFERENSI}

Cahyono, L. A., Winarno, W. W., \& Nugroho, H. A. (2015). Virtualisasi medis: Analisis kecenderungan masyarakat mencari informasi kesehatan di internet. SEMNASTEKNOMEDIA

ONLINE, 3(1), 1-2.

Dasar, K. (2012). Sistem informasi kesehatan.

Herlambang, T. W., Aknuranda, I., \& Saputra, M. C. (2017). Pengembangan Sistem Informasi Kesehatan Berbasis Web Berdasarkan Model Organisasi Dan Manajemen Kesehatan Primer "ANDAL". Jurnal Pengembangan Teknologi Informasi dan Ilmu Komputer e-ISSN, 2548, 964X.

Pratama, S. (2019). Aplikasi Job Fair Berbasis Web Pada Dinas Sosial Tenaga Kerja dan Transmigrasi Kalimantan Selatan. Technologia: Jurnal Ilmiah, 10(1), 47-52.

Pratama, S. (2016). Penerapan Aplikasi Posyandu Mawar Kelurahan Simpang Empat. Technologia: Jurnal Ilmiah, 7(4).

Pratama, S. (2016). Penerapan Sistem Informasi Posyandu Mawar Kelurahan Simpang Empat. Technologia: Jurnal Ilmiah, 7(4).
Sanjoyo, R. (2007). Sistem Informasi Kesehatan. KTI. Yogyakarta: UGM.

Wahono, B. B. (2015). Perancangan tatakelola teknologi informasi untuk peningkatan layanan sistem informasi kesehatan (studi kasus dinas kesehatan kabupaten jepara). Simetris: Jurnal Teknik Mesin, Elektro dan Ilmu Komputer, 6(1), 101110. 